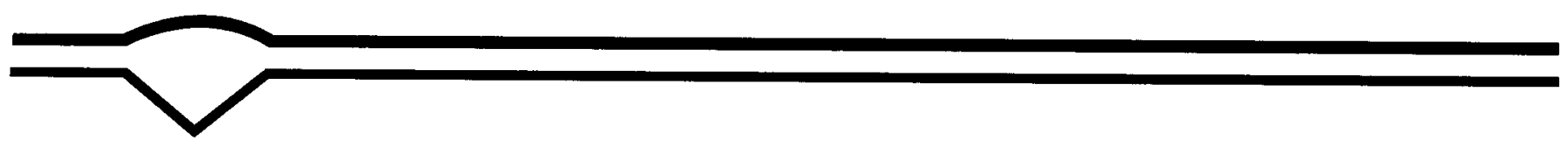

\title{
Chemokine and inflammatory cytokine changes during chronic wound healing
}

\author{
DAVID P. FIVENSON, MDa; DUYEN T. FARIA, DO'; BRIAN J. NICKOLOFF, MD, PhD ; PETER J. POVERINI, DDS ; \\ STEVEN KUNKEL, PhD'; MARIE BURDICK, MS'; ROBERT M. STRIETER, MDd
}

\begin{abstract}
Wound healing is a complex process resulting from an interplay of processes including coagulation, inflammation, angiogenesis, and epithelialization. The chemokine family has been shown to contain members that are potent regulators of many of these pathways. Because we have previously shown that chemokines "pool" in biologic wound dressings, we studied the levels of CXC and CC chemokines, along with key inflammatory mediators, serially from a group of patients undergoing therapy for chronic venous leg ulcers. After 8 weeks, all patients had marked clinical healing of their ulcers (median $63.3 \%$ reduction in size) with two of 10 completely healed. Wound fluids extracted from dressings showed high levels of platelet factor- 4 and interferon- $\gamma$-inducible protein, with a trend toward increases in the ratio of the sums of the angiogenic versus angiostatic CXC chemokines $(p=0.082)$ in the tissues collected from the center of the ulcers during wound closure. Neutrophil-activating peptide-2 and interleukin- 8 accounted for the most changes in wound fluid angiogenic chemokines, with significant differences both as compared with baseline levels and with patients' plasma level noted at various time points between weeks 0 and 8 . The level of angiostatic (cont.)
\end{abstract}

From the Department of Dermatology, Henry Ford Health System, Detroit, Mich. : Department of Pathology, Loyola University Medical Center, Chicago, III.;; and the Departments of Pathologyc and Medicine, ${ }^{a}$ University of Michigan Medical Center, Ann Arbor, Mich.

Presented in part at the Society for Investigative Dermatology, May 27, 1995, Chicago, III. (Fivenson D, Faria D. Nickoloff B, Poverini P, Kunkel S, Burdick M, Strieter R. CXC chemokine efflux during chronic wound healing: critical role of the ELR motif in angiogenesis. Jinvest Dermatol 1995:104:625, and Fivenson D, Faria D. Nickoloff B, Poverini P, KunkelS, Burdick M, Strieter R. Anti-inflammatory cytokines increase during healing of chronic venous ulcers favoring progression to a macrophage-dominated late inflammatory/early proliferative phase of wound repair. J Invest Dermatol 1995; 104:591.)

Reprint requests: David P. Fivenson, MD, Division Head, Dermatology Research, Department of Dermatology, Henry Ford Hospital, 2799 W. Grand Blvd., Detroit, MI 48202.

Copyright (C) 1997 by The Wound Society.

$1067-1927 / 97 / \$ 5.00+0 \quad 36 / 1 / 86424$
BTG $\quad$ TThromboglobulin

CTAP-III Connective tissue-activating peptide-III

CVIU Chronic venous insufficiency ulcer

ENA-78 Epithelial neutrophil-activating peptide 78

GCP2 Granulocyte chemotactic protein-2

GRO $\alpha$ Growth-regulated gene product

IL-8 Interleukin-8

IP10 Interferon- $\gamma$-inducible protein 10

IRAP Interleukin-1 receptor antagonist protein

MCP-1 Monocyte chemoattractant protein-1

MIG Monokine- $\gamma$-interferon-inducible gene

MIP-1 $\alpha \quad$ Macrophage inflammatory protein-1 $\alpha$

MIP-1 $\beta \quad$ Macrophage inflammatory protein-1 $\beta$

NAP2 Neutrophil-activating peptide-2

PBS Phosphate-buffered saline solution

PF4 Platelet factor-4

RANTES Regulated on activation, normal $\mathrm{T}$ expressed and secreted

TGF- $\beta \quad$ Transforming growth factor- $\beta$

TNF- $\alpha$ Tumor necrosis factor- $\alpha$ 
chemokines, interferon- $\gamma$ inducible protein 10 and platelet-activating-4, fell most significantly between weeks 0 and 3 as compared with plasma levels. The observed shift toward angiogenic $\mathrm{CXC}$ chemokines suggests that effective healing in chronic venous insufficiency ulcers appears to "move" the ulcer bed toward a state more conducive to epithelialization, characteristic of the proliferative phase of wound healing. $\mathrm{CC}$ chemokines were also elevated at baseline in the wound fluid samples as compared with the patients' plasma levels. Macrophage inflammatory protein-1 $\beta$ and regulated on activation, normal T expressed and secreted (RANTES) levels decreased with healing, whereas there were significant increases in the tissue levels of monocyte chemoattractant protein-1 and macrophage inflammatory protein- $1 \alpha$ over the first 4 weeks of therapy ( $\rho \leq 0.05$ for both). Coincident with these changes was a steady increase in the ratio of interleukin- $1 \beta$ /interleukin-1 receptor antagonist protein in the ulcer center tissues, which also correlated with healing $(p<0.05)$ as compared with a decreasing ratio at the ulcer edge, and a biphasic response in the wound fluids. These findings suggest that advanced wound care techniques help move the ulcer from a chronic inflammatory state into one more characteristic of the late inflammatory/early proliferative phase of wound healing Chemokines may play a critical role in the pathogenesis of chronic venous ulcers through their effects on angiogenesis and/or the progression of inflammatory reactions at the site of injury. (WOUND REP REG 1997;5:310-22)

Normal wound healing involves the coordinated interplay of cells, extracellular matrix, and an ever-expanding host of mediators. The cellular physiology of wound repair includes the coordinated stimulation of blood vessel growth (angiogenesis), keratinocyte and fibroblast proliferation, production of epithelial and endothelial basement membrane zones, and connective tissues (e.g., collagens, ground substance) ${ }^{1-4}$ In skin, there are three well-recognized phases of wound repair: the inflammatory phase, the tissue formation or proliferative phase, and the tissue remodeling phase. ${ }^{5,6}$ Although these phases are not necessarily mutually exclusive, they are somewhat distinct and help to provide the investigator with a reasonable approach to understanding normal versus abnormal wound repair.

Chronic wounds appear to be, at least in part, mediated by dysregulation of cytokines. ${ }^{1,2}$ Some investigators have also suggested that the nonhealing state is due to a disruption of the precise coordination of the temporal expression of these mediators and not necessarily an absolute absence of any particular one. ${ }^{7}$ One of the most common forms of chronic wounds is the chronic venous insufficiency ulcer (CVIU). When reviewed in 1985, these were shown to affect as many as 500,000 patients and cost the U.S. Health Care System in excess of $\$ 250$ million per year. ${ }^{5}$ Among the potentially important families of mediators involved in orchestrating effective wound healing, and targets for dysregulation in the pathogenesis of chronic wounds, are the chemokines. ${ }^{6,8,9}$

As their name suggests, these factors were originally described because of their principal effects on chemotaxis. The chemokines consist of a number of distinct 8- to $10-\mathrm{kd}$ cytokines that exhibit from $20 \%$ to $55 \%$ homology in amino acid sequence. ${ }^{8}$ All chemokines have four cysteine residues that form two disulfide bridges. Members of the CXC chemokine subfamily are located on chromosome 4, and share two conserved cysteines separated by one unconserved amino acid, hence the designation $C-X-C$. This family includes interleukin-8 (IL-8), growth-regulated gene product $(\mathrm{GRO} \alpha)$, platelet basic protein and its cleavage products (connective tissue-activating peptide-III, [CTAP-III]), $\beta$-thromboglobulin ( $\beta T G$ ), neutrophil-activating peptide-2 (NAP2); interferon- $\gamma$-inducible protein (IP10), epithelial neutrophil-activating peptide-78 (ENA-78), granulocyte chemotactic protein-2 (GCP2), and monokine- $\gamma$-interferon-inducible gene (MIG) ${ }^{8-11}$ IL-8, ENA-78, NAP2, and GRO $\alpha$ all share a Glu-Leu-Arg (ELR) motif preceding the first cysteine in the N-terminus. ${ }^{8,10}$ These ELR+ CXC chemokines have been associated with significant angiogenesis function in vitro, as well as sharing abilities to stimulate both keratinocyte proliferation and migration. ${ }^{11,12}$ CXC chemokines-including IP10, MIG, and platelet factor-4 (PF4)-lack this ELR motif (referred to as ELR- CXC chemokines) and have been shown to be angiostatic. ${ }^{12-15}$

The CC chemokine subfamily of genes are located on chromosome 17, and have adjacent conserved cysteine amino acid residues, hence the designation $C C$. These proteins include monocyte chemoattractant proteins 1 to 4 (MCP-1 to -4), macrophage inflammatory protein-1 $\alpha$ and $1 \beta$ (MIP- $1 \alpha$ and MIP-1 $\beta$ ), regulated on activation, normal T expressed and secreted (RANTES), and I-309. Members of this subfamily were originally described for their chemotactic activity on monocytes and macrophages. ${ }^{8}$ The effects of CC chemokines also have been expanded recently to include T-cell chemotaxis and mitogenesis, fibrogenesis, and control of HIV infection. ${ }^{10,13,16}$ These chemokines also have been associated with a variety of important functions with relevance to wound healing. ${ }^{8,11,17-20}$

In this study, we have investigated the tissue and wound fluid levels of representative proinflammatory, anti-inflammatory, and macrophage-related cytokines, along with representative $\mathrm{CXC}$ and $\mathrm{CC}$ chemokines in a 
series of patients with CVIU. We report that the angiostatic chemokines, PF4 and IP10, are abnormally elevated in both tissues and wound fluids of these patients at baseline as compared with normal skin levels. These ELR- chemokines remained elevated throughout an 8-week observation, but were found to decrease in relation to the amounts of ELR+ chemokines in association with clinical wound healing. We also report that CVIUs are characterized by aberrantly high levels of the proinflammatory mediator, IL-1 $\beta$. Healing is shown to be associated with a shift toward macrophage and antiinflammatory cytokine profiles that parallel the progression to later stages of wound healing. Healing was associated with decreases in IL-1 $\beta$, MIP-1 $\beta$, and RANTES along with increases in IL-1 receptor antagonist protein (IRAP), IL-10, MIP-1 $\alpha$, and MCP-1. These data suggest that CVIUs may be due to the persistence of a chronic inflammatory state that prevents the normal progression of wound healing. Our results suggest that the chemokines may be important in the pathogenesis of CVIUs, and a shift in their relative ratios may be an important part of the change that occurs when a CVIU begins to heal.

\section{MATERIAL AND METHODS}

All patients enrolled in the study gave written and informed consent to participate under protocols approved by the Henry Ford Health System Human Rights Committee. Diagnosis of CVIU was confirmed by photoplegthymography ( $<20 \mathrm{sec})$ and ankle-brachial index (>0.65). All patients underwent a prophylactic 2 -week course of antibiotics, and local debridement was performed with curettage of undermined edges to remove devitalized tissues and fibrin before baseline evaluation. Each patient was evaluated at baseline, and then weekly with photography and surface area tracings on acetate paper to calculate wound area. Each wound was dressed with a standard regimen of a layer of nonadherent dressing, covered by a hydrofoam pad (Allevyn; Smith and Nephew United, Largo, Fla.) and then wrapped with a graduated compression dressing bandage of zinc-oxide paste-impregnated gauze. A 2-mm punch biopsy of normal leg skin (above the knee), ulcer edge, and ulcer center was obtained at baseline. Repeated biopsies at the ulcer edge and center were obtained at weeks 4 and 8, respectively. At baseline (W0) and weekly for 8 weeks (W1 to W8), the central 2-cm diameter of the hydrofoam dressing directly overlying the ulcer center was collected and stored at $-70^{\circ} \mathrm{C}$ for subsequent extraction of wound fluid.

\section{Specimen preparation}

Wound fluid samples were all extracted from Allevyn dressings by homogenization in $2 \mathrm{ml}$ of sample buffer (sterile phosphate-buffered saline solution [PBS] containing a cocktail of $1 \%$ phenylmethylsulfonyl fluoride, $0.001 \%$ antipain,
$0.001 \%$ aprotinin, $0.001 \%$ leupeptin, $0.001 \%$ pepstatin A) followed by sonication. ${ }^{15}$ This technique has been shown previously to result in recovery of viable quantities of cytokines. ${ }^{21} \mathrm{We}$ also performed pilot studies in which purified chemokines were added to the Allevyn dressing, and then were successfully reextracted with high recovery rates. ${ }^{21}$ Tissue samples were similarly processed by homogenization in $2 \mathrm{ml}$ of sample buffer. All samples were centrifuged to remove debris and then filtered through $1.2-\mu \mathrm{m}$ filters (Gelman Sciences, Ann Arbor, Mich.) before analysis. Total protein content of each tissue sample was determined by the Lowry method to normalize for differences in yield between samples.

\section{ELISA quantitation of chemokines and cytokines} IL-8, IP10, ENA-78, GRO $\alpha$, PF4, NAP2, MIP-1 $\alpha$, MIP-1 $\beta$, MCP-1, RANTES, IL-10, transforming growth factor- $\beta$ (TGF- $\beta$ ), IL-1 $\beta$, IRAP, IL-6, and tumor necrosis factor- $\alpha$ (TNF- $\alpha$ ) were quantified using a modification of a double ligand ELISA method. ${ }^{11,18,19}$ Flat-bottomed 96-well microtiter plates were coated with $50 \mu \mathrm{L} /$ well rabbit anticytokine antibodies (Sigma Chemical Co., St. Louis, Mo.) $\left(1 \mu \mathrm{g} / \mathrm{ml}\right.$ in $0.6 \mathrm{~mol} / \mathrm{L} \mathrm{NaCl}, 0.26 \mathrm{~mol} / \mathrm{L} \mathrm{H}_{3} \mathrm{SO}_{4}$ and $0.08 \mathrm{~N}$ $\mathrm{NaOH}, \mathrm{pH} 9.6$, for 16 hours at $4^{\circ} \mathrm{C}$ ), and then washed with PBS ( $\mathrm{pH} 7.5$ ) containing $0.05 \%$ Tween-20 (Sigma) (wash buffer). Nonspecific binding sites on microtiter plates were blocked with $2 \%$ bovine serum albumin in PBS and incubated for 90 minutes at $37^{\circ} \mathrm{C}$. Plates were rinsed four times with wash buffer, and samples were added $\left(50 \mu \mathrm{l} /\right.$ well) and incubated for 1 hour at $37^{\circ} \mathrm{C}$. Plates were washed four times with wash buffer, and 50 $\mu \mathrm{l} /$ well of biotinylated rabbit anticytokine antibodies were added for 30 minutes at $37^{\circ} \mathrm{C}$. They were again washed, and the chromogen substrate added. Plates were incubated at $25^{\circ} \mathrm{C}$, and the reaction terminated with $50 \mu \mathrm{L}$ well of $3 \mathrm{~mol} / \mathrm{L} \mathrm{H}_{3} \mathrm{BO}_{4}$ solution. Results were analyzed at $490 \mathrm{~nm}$ in an ELISA reader and sensitivity was consistently $50 \mathrm{pg} / \mathrm{ml}$ or less.

\section{Data analysis}

All tissue results were represented after correction for the total protein content. The individual samples were correlated to the percentage healing determined by the change in surface area of the weekly acetate tracings. Spearman's rank correlation coefficients were generated because the data were not normally distributed. The mean changes in individual sample sites (ulcer edge, ulcer center, and wound fluid extracted from the dressings) over time were analyzed by Student's $t$ test. Tissue samples were compared between weeks 0 and 4 . Mean changes in wound fluids were analyzed between weeks 0 and 8 . Because much of the data also were not normally distributed, median levels are presented. Baseline mean/ median differences between these sites were also analyzed by Student's paired $t$ test or Wilcoxon's sign rank test for data that departed from a normal distribution. 
Table 1. CXC chemokine levels in plasma and wound fluid and tissue extracts from patients with CVIU at the initiation of the study

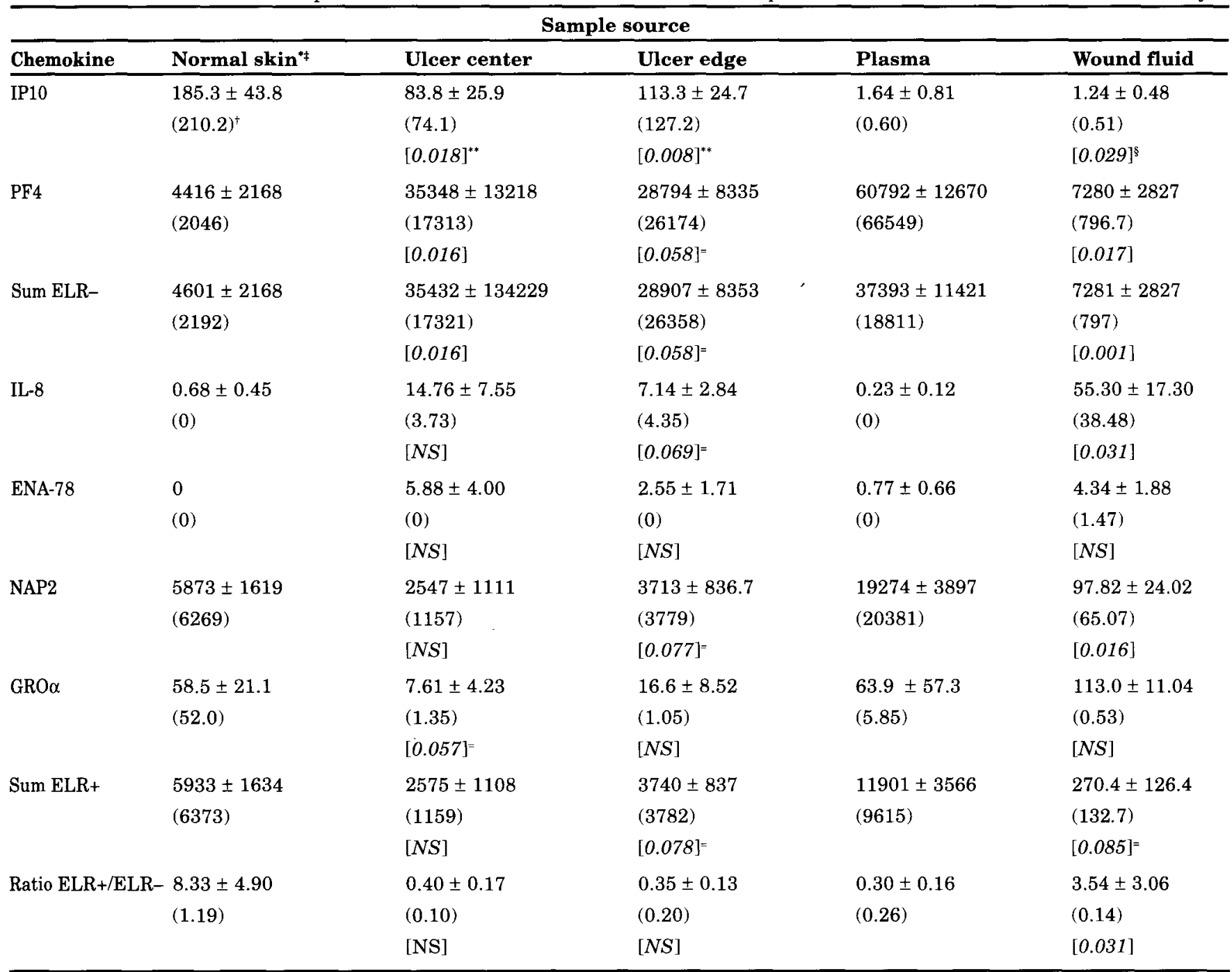

NS, Not significant; $=$, indicates significant trend.

Values indicate mean $\pm \mathrm{SE}$

tValues in parentheses beneath mean $\pm \mathrm{SE}$ indicate median.

${ }^{\ddagger}$ All tissue results are expressed as $\mathbf{n g} / \mathrm{ml} / \mathrm{mg}$ total protein recovered after extraction of a 2-mm punch biopsy in $2 \mathrm{ml}$ of buffer. Patient plasma and chronic wound fluid samples are expressed in $\mathrm{ng} / \mathrm{ml}$. Chronic wound fluids represent the total amount of cytokine that accumulated in the wound dressing over a 7-day period of time and then extracted into $2 \mathrm{ml}$ of buffer.

"Italic values in brackets beneath mean $\pm \mathrm{SE}$ in this column indicate significance level of this value versus normal skin.

Italic values in brackets beneath mean $\pm \mathrm{SE}$ in this column indicate significance level of this mean versus plasma.

$t$-Tests were interpreted liberally because of the overall modest sample size. Significance was defined as $p$ $\leq 0.05$, and significant trends were defined as $0.10 \geq p$ $>0.05$. Wound fluid levels were compared with tissue levels and plasma levels for individual cytokines versus time, the ratio of the sums of ELR+ to ELRchemokines and for the ratio of IL-1 $\beta$ to IRAP. No analysis of biologic activity was performed on the recovered wound fluid proteins. Therefore, tissue and plasma values represent a single time point. Wound fluid levels represent 7 -day accumulations each, less any loss caused by proteolytic degradation.

\section{RESULTS}

Fourteen patients were evaluated at baseline; with 10 of these followed weekly for 8 weeks. Size of the leg ulcers in these patients ranged from 2.0 to $85.4 \mathrm{~cm}^{2}$, with a mean surface area of $26.5 \pm 6.6 \mathrm{~cm}^{2}$. Measurement of the ulcers at week 8 indicated a range of from completely healed $(n=2)$ to $50.8 \mathrm{~cm}^{2}$, with a mean size of $12.4 \pm 3.7 \mathrm{~cm}^{2}$. This equated to a mean $46.8 \pm 17.5 \%$ (median $=63.3 \%$ ) reduction in ulcer surface area over the 8-week study in these 10 patients. After 6 months, $(n=5)$ two additional patients had healed, and the remaining three had a mean ulcer area of $7.8 \mathrm{~cm}^{2}$. 
Table 2. CC chemokine and proinflammatory cytokine levels in plasma and wound and tissue extracts from patients with CVIU at the initiation of the study

\begin{tabular}{|c|c|c|c|c|c|}
\hline \multicolumn{6}{|c|}{ Sample source } \\
\hline Cytokine & Normal skin** & Ulcer center & Ulcer edge & Plasma & Wound fluid \\
\hline \multirow[t]{3}{*}{ IL-10 } & 0 & $1.27 \pm 1.23$ & ND & 0 & $145.9 \pm 140.5$ \\
\hline & $(0)^{\dagger}$ & $(0)$ & & $(0)$ & $(0.07)$ \\
\hline & & {$[N S]^{* *}$} & & & {$[N S)^{8}$} \\
\hline \multirow[t]{3}{*}{ TNF- $\alpha$} & $0.31 \pm 0.31$ & $0.59 \pm 0.46$ & $\mathrm{ND}$ & $1.94 \pm 1.66$ & $0.24 \pm 0.07$ \\
\hline & $(0)$ & $(0)$ & & (0) & $(0.14)$ \\
\hline & & {$[N S]$} & & & {$[0.038]$} \\
\hline \multirow[t]{3}{*}{ IL-6 } & 0 & $17.10 \pm 8.97$ & $\mathrm{ND}$ & $4.45 \pm 3.07$ & $2.08 \pm 0.90$ \\
\hline & $(0)$ & $(0)$ & & $(0)$ & $(0.44)$ \\
\hline & & {$[0.089]=$} & & & {$[N S]$} \\
\hline \multirow[t]{3}{*}{ TGF- $\beta$} & $6.33 \pm 6.33$ & $7.50 \pm 5.27$ & $1.89 \pm 1.89$ & $28.80 \pm 16.25$ & $0.07 \pm 0.05$ \\
\hline & $(0)$ & $(0)$ & $(0)$ & $(6.60)$ & $(0)$ \\
\hline & & {$[N S]$} & {$[N S]^{* *}$} & & {$[0.031]$} \\
\hline \multirow[t]{3}{*}{ MCP-1 } & 0 & $0.53 \pm 0.23$ & $0.51 \pm 0.20$ & 0 & $0.15 \pm 0.04$ \\
\hline & $(0)$ & $(0.15)$ & $(0.22)$ & $(0)$ & $(0.06)$ \\
\hline & & {$[0.061]=$} & {$[0.033]$} & & {$[N S]$} \\
\hline \multirow[t]{3}{*}{ MIP-1 $\alpha$} & $0.08 \pm 0.08$ & $0.36 \pm 0.09$ & $0.28 \pm 0.12$ & 0 & $19.00 \pm 18.30$ \\
\hline & $(0)$ & $(0.44)$ & $(0.20)$ & $(0)$ & $(0.06)$ \\
\hline & & {$[0.085]^{=}$} & {$[N S]$} & & {$[N S]$} \\
\hline \multirow[t]{3}{*}{ MIP-1 $\beta$} & 0 & $0.14 \pm 0.06$ & $0.098 \pm 0.064$ & 0 & $16.04 \pm 12.37$ \\
\hline & $(0)$ & $(0)$ & $(0)$ & $(0)$ & $(0.14)$ \\
\hline & & {$[0.05]$} & {$[N S]$} & & {$[N S]$} \\
\hline \multirow[t]{3}{*}{ RANTES } & 0 & $3.70 \pm 3.16$ & $2.51 \pm 1.93$ & $7754 \pm 7206$ & $0.73 \pm 0.49$ \\
\hline & $(0)$ & $(0)$ & $(0)$ & $(558.2)$ & $(0.15)$ \\
\hline & & {$[N S]$} & {$[N S]$} & & {$[0.003]$} \\
\hline \multirow[t]{3}{*}{ IL- $1 \beta$} & $0.08 \pm 0.08$ & $21.89 \pm 21.03$ & $2.09 \pm 0.89$ & $0.03 \pm 0.02$ & $5.21 \pm 3.98$ \\
\hline & $(0)$ & $(0.61)$ & $(1.0)$ & $(0)$ & $(0.76)$ \\
\hline & & {$[0.031]$} & {$[0.008]$} & & {$[0.055]=$} \\
\hline \multirow[t]{3}{*}{ IRAP } & $22.48 \pm 5.02$ & $8.48 \pm 3.11$ & $14.24 \pm 3.62$ & $6.26 \pm 3.03$ & $22.76 \pm 17.85$ \\
\hline & $(\mathbf{1 7 . 5 8 )}$ & $(4.02)$ & $(16.17)$ & $(1.60)$ & $(2.32)$ \\
\hline & & {$[0.032]$} & {$[0.083]=$} & & {$[N S]$} \\
\hline \multirow[t]{3}{*}{ IL-1 $\beta /$ IRAP } & $0.08 \pm 0.08$ & $0.84 \pm 0.29$ & $1.79 \pm 0.59$ & $0.01 \pm 0.01$ & $0.31 \pm 0.16$ \\
\hline & $(0)$ & $(0.77)$ & $(1.23)$ & $(0)$ & $(0.06)$ \\
\hline & & {$[0.074]=$} & {$[0.016]$} & & {$[N S]$} \\
\hline
\end{tabular}

$N D$, Not done; $N S$, not significant; =, indicates significant trend.

*Values indicate mean $\pm \mathrm{SE}$.

Values in parentheses beneath mean $\pm \mathrm{SE}$ indicate median.

${ }^{\ddagger}$ All tissue results are expressed as $\mathrm{ng} / \mathrm{ml} / \mathrm{mg}$ total protein recovered after extraction of a 2 -mm punch biopsy in $2 \mathrm{ml}$ of buffer. Patient plasma and chronic wound fluid samples are expressed in $\mathrm{ng} / \mathrm{ml}$. Chronic wound fluids represent the total amount of cytokine that accumulated in the wound dressing over a 7-day period of time and then extracted into $2 \mathrm{ml}$ of buffer.

"* Italic values in brackets beneath mean $\pm \mathrm{SE}$ in this column indicate significance level of this value versus normal skin.

${ }^{\S}$ Italic values in brackets beneath mean $\pm \mathrm{SE}$ in this column indicate significance level of this mean versus plasma.

CXC chemokines in the untreated CVIU (baseline) In all samples, NAP2 was the ELR+ CXC chemokine in highest tissue content, and PF4 was the highest ELR-CXC chemokine (Table 1). The prominent PF4 content in nor- mal skin was unexpected, because platelet activation (the major source of $\mathrm{PF} 4$ ) is not a characteristic of normal skin. ${ }^{12}$

At baseline, all CVIUs were characterized by much higher levels of PF4 and IP10 as compared with IL-8, 

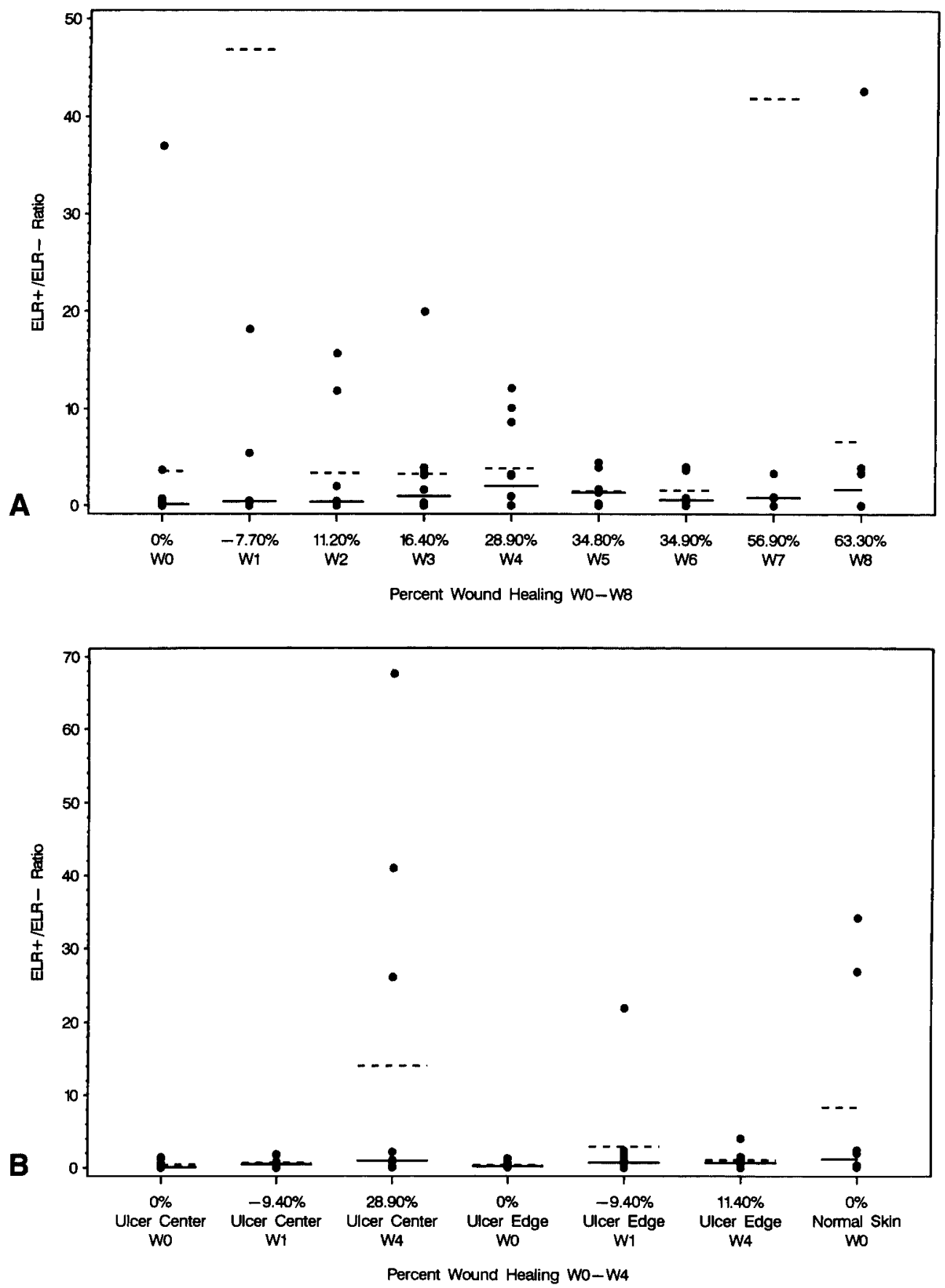

Figure 1 ELR+/ELR- ratios as function of healing during CVIU treatment. Ratio of aggregate sum of ELR+/ELR- chemokines ((IL-8 + NAP2 + ENA-78 + GRO $) /(P F 4+I P 10))$ in samples from patients with CVIUs compared with percentage wound closure. A, Dot plot of individual wound fluid ELR+I ELR- ratios as function of healing during CVIU treatment. Wound fluids extracted from central portion of overlying hydrofoam dressing show biphasic ratio with wound closure. Many values overlap, giving appearance of fewer data points at each time point. W1 and W7 each had one data point that was off scale. B, Individual tissue ELR+/ELR- ratios as function of healing. Ulcer center versus ulcer edge ELR+/ELR- CXC chemokine ratios show increasing ratio in ulcer center as compared with stabilizing ratio at ulcer edge. Many values overlap, giving appearance of fewer data points at each time point. Solid lines at each time point, median value; dashed lines, mean value $(n=10)$ 


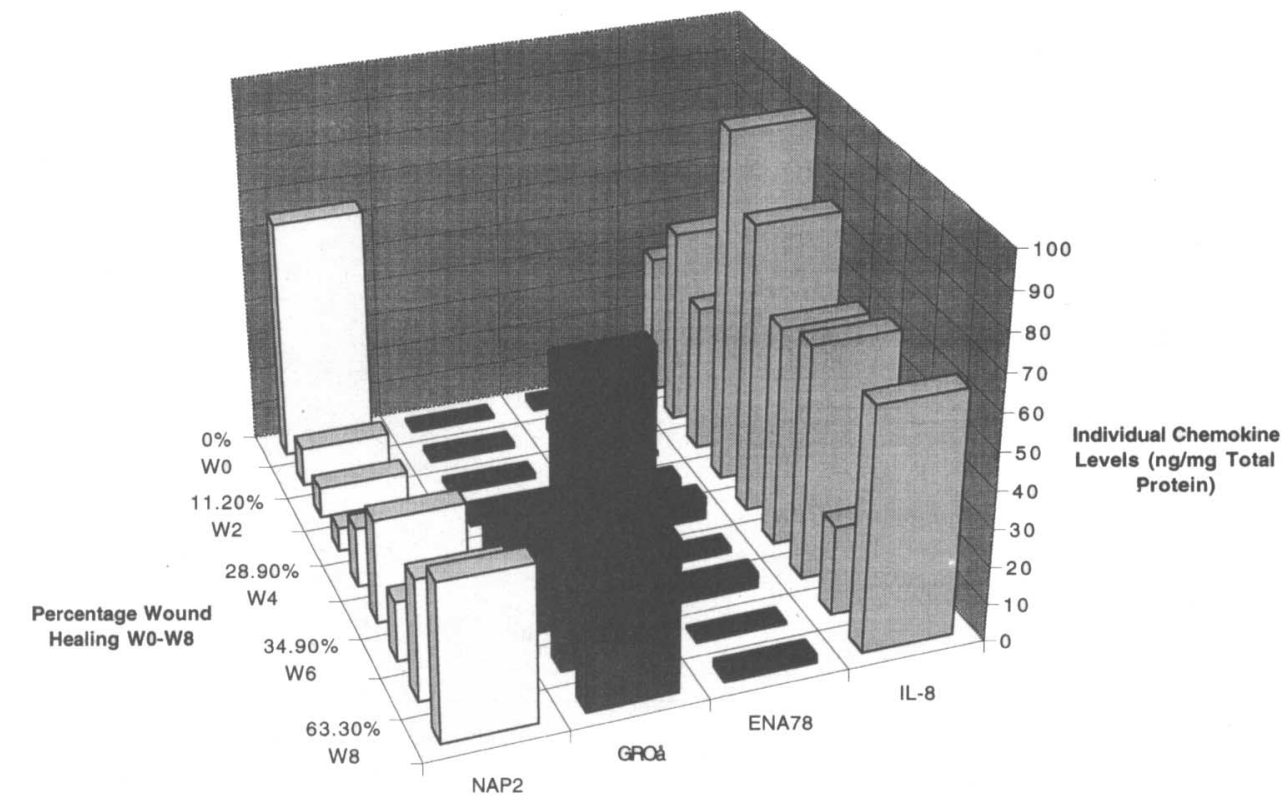

Figure 2 Median individual $\mathrm{CXC}$ chemokine levels in wound fluids as function of healing during CVIU treatment. Median values of each ELR+ CXC chemokine (IL-8, NAP2, ENA-78, and GRO $\alpha$ ) in samples from patients with CVIUs compared with percentage wound closure. IL-8, NAP2, and GRO $\alpha$ levels steadily increased throughout 8 -week observation period $(n=10)$.

GRO $\alpha$, NAP2, and ENA-78 (Table 1). To study their aggregate effects, the sum of the protein levels for the ELR+, ELR-, and ratio of ELR+/ELR- chemokines were calculated for each sample. As shown in Table 1, the ELR+/ ELR- ratio at baseline between ulcer sites was not statistically significant ( $p=0.16$ ). None of the chemokines showed statistically different levels between the ulcer edge versus ulcer center at baseline. The median ratio in the subjects' normal skin at baseline was 1.90 , whereas plasma from CVIU patients and healthy controls (data not shown) had a median ELR+/ELR- ratio of approximately 0.50 . Table 1 summarizes these baseline findings. Only GRO $\alpha$ levels in the ulcer center showed a significant trend versus normal skin at baseline, whereas both PF4 and IP10 were significant versus normal skin. Comparison between the ulcer edges and normal skin showed significant trends for all CXC values except GRO $\alpha$ and ENA-78. In the wound fluids at baseline, IP10, PF4, NAP2, IL-8 and the sums of ELR+ and ELR- chemokines and their ratio, were all found to be significantly different compared with normal plasma.

\section{CXC chemokine changes during the initiation of wound healing in CVIUs}

Over the 8-week observation period, there were prominent changes in the ELR+/ELR- ratio detected in the wound fluid and tissue samples, which were associated with the percentage of healing. In Figure 1, the changes in ELR+/ELR- ratio are compared with healing in the wound fluids (Figure $1, A$ ), the ulcer center, and the ulcer edge (Figure $1, B$ ). Here, there appears to be a com- partmental effect that is associated with wound closure. At the wound margins, there is a stabilization in the ELR+/ELR-ratio in association with the decreasing surface area of the ulcer, whereas the wound centers showed a steady increase in this ratio.

At the end of the 8-week observation period, only changes in wound fluid IL-8 levels showed a significant trend ( $p=0.09$ ); however, several of the CXC chemokine levels were significantly different as compared with baseline during this time (Figure 2). In particular, NAP2 changes over weeks 2 to 5 were significantly different from baseline $(p \leq 0.05$ ), whereas changes in IL-8 (weeks 2 to 4,8$)$ were showing significant trends $(0.1 \geq p>0.05)$ (Figure 2). Neither IP10 or PF4, nor their sum, was significantly changed at any time point when compared with baseline levels.

However, when compared with each patient's plasma at baseline, there were significant differences noted during the 8 weeks of observation for IP10 (weeks 0 to 7), PF4 (weeks 0 to 3 and 6), the ELRsum (weeks 0 to $8, p \leq 0.05$ ), IL-8 (weeks 0 to 2, 7, and 8), NAP2 (weeks 0 , and 2 to 4), and GRO $\alpha$ (weeks 1 to 3 ) (Figure 2). The absolute changes in tissue levels between week 0 and 4 for IP10 $(p=0.071)$, NAP2 $(p=0.079)$, and the ELR+ sum $(p=0.080)$ were also found to have a significant trend in the ulcer edge samples, whereas only the NAP2 $(p=0.060)$ and ELR+ sum ( $p=0.067)$ changes approached a significant trend for the same period from the ulcer center samples.

Thus, each chemokine appears to have a unique expression profile during the wound healing process. In- 


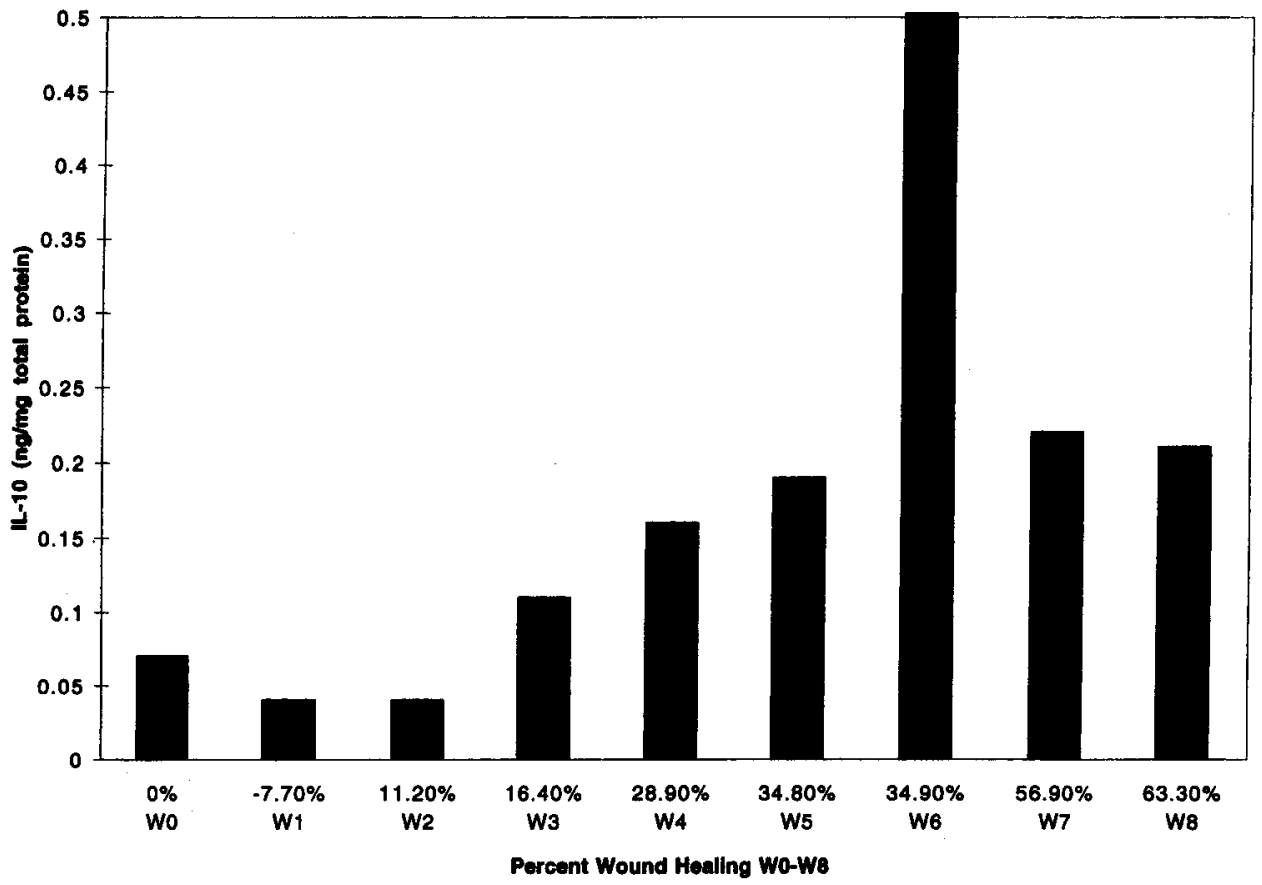

Figure 3 Wound fluid IL-10 levels as function of healing during CVIU treatment. Wound dressing samples collected from patients observed over 8 -week period. Median percentage healing compared with individual detectable levels of IL-10 after normalization for total protein in all samples. Gradual but insignificant increase in IL-10 level noted after approximately $10 \%$ healing (week 3 ), which continued throughout observation time. Many values overlap, giving appearance of fewer data points at each time point. Solid lines at each time point, median value; dashed lines, mean value $(n=10)$

creases in IL-8, GRO $\alpha$, and NAP2, combined with decreases in IP10 and PF4, resulted in a net increase of ELR+ chemokine levels as the wounds started to close. Rigorous statistical analysis revealed statistically significant correlation only between the percentage of wound closure and decreases in PF4 and the total ELR- ( $p \leq$ 0.05 for each) from the ulcer center samples. The increasing ratio of ELR+/ELR- found in the ulcer center showed a significant trend in correlation with the degree of wound closure $(p=0.08$ ), whereas none of the other trends noted for these mediators in either the edge skin or wound dressings was significant in relation to healing.

In normal skin, there were also fluctuating levels of these mediators during the healing process, suggesting that there are systemic effects attributable to the wound healing process. Healing of the CVIUs at a distal site was associated with a trend toward significance with the decreases in normal skin levels of IL-8, NAP2, and the sum of the ELR+ chemokines between weeks 0 and 4 ( $p=0.07,0.08$, and 0.08 , respectively).

\section{Inflammatory cytokine levels in the untreated CVIU}

Baseline levels of the CC chemokines MCP-1, MIP-1 $\alpha$, MIP-1 $\beta$, and RANTES, along with nonchemokine cytokines important in the initiation and regulation of tissue inflammation (IL-1 $\beta$, IRAP, IL-6, IL-10, TGF- $\beta$, and TNF- $\alpha$ ), are summarized in Table 2. Elevated IL-6 levels were shown to have a trend toward significance in the ulcer centers as compared with normal skin $(p=0.089$ ), whereas IL-6 levels were variable in the edge samples and in the wound fluids. IL-6 was the only cytokine that showed a significant trend in the differences between baseline levels in ulcer center versus edge tissue samples $(p=0.089)$. TNF- $\alpha$ levels in the baseline samples from the dressings were significantly elevated ( $p \leq 0.05$ ), but were generally undetectable in the small tissue biopsies analyzed. IL10 levels also were found to vary widely and were very high in some of the dressing samples at baseline (mean W0 IL-10 in wound fluid level $=145.9 \pm 140.5$, median $=0.069$; Figure 3 ), whereas they were barely detectable in tissue samples. TGF- $\beta$ levels in wound fluids were lower than expected based on other reports of the role of TGF- $\beta$ in wound healing, ${ }^{1,7}$ with only the wound fluid levels of TGF- $\beta$ being significantly elevated in comparison with the patients' normal plasma levels at baseline $(p \leq 0.05)$.

IL-1 $\beta$ levels were higher at baseline in ulcer tissues and wound fluid samples (Table 2 and Figures 4, $A$ and $4, B$ ) as compared with normal skin or plasma. The ulcer edge and center differences were significant ( $p \leq 0.05$ for both, Figure $4, B$ ), whereas wound fluid 

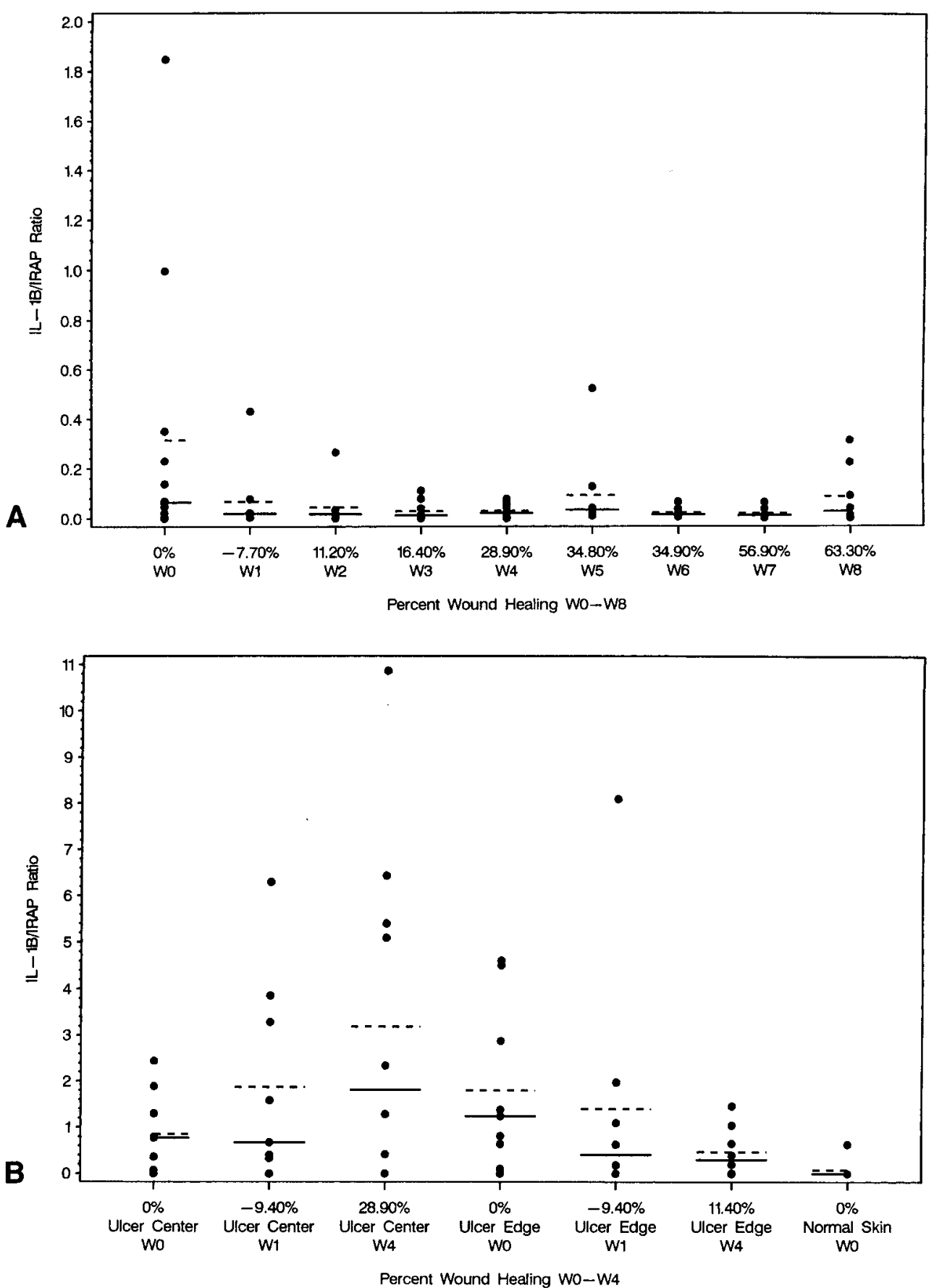

Figure 4 Median IL-1ß/IRAP ratio as function of healing during CVIU treatment. A, Dot plot of individual wound fluid IL-1B/IRAP ratios as function of healing during CVIU treatment. Dressing extracts show biphasic response as compared with wound closure throughout 8-week observation period. B, Individual tissue IL-1 $\beta$ /IRAP ratios as function of healing. Gradual increase in ulcer center levels seen, as compared with steady decreases in levels of ratio in ulcer edge over 4week observation period. Many values overlap, giving appearance of fewer data points at each time point. Solid lines at each time point, median value; dashed lines, mean value $(n=10)$

levels showed a significant trend $(p=0.055)$. The natural inhibitor of IL-1, IRAP, had a significant trend toward lower levels at baseline only in the tissues, as compared with normal skin or plasma. When the ratio of IL-1 $\beta /$ IRAP was used to compare the balance between these pro- and anti-inflammatory mediators, it was significantly elevated in the ulcer edge and center, but not in the wound fluid samples, as compared with normal skin and plasma at baseline (edge, $p=0.016$; center, $p=$ 0.074 ; wound fluid, $p=0.338$; Table 2). 


\section{Cytokine trends during CVIU treatment}

Changes in IL-6 levels in the ulcer edges between baseline and week 4 also showed a significant trend ( $p$ $=0.062$ ). The wound fluid IL-10 levels gradually increased after week 3 ( $11.2 \%$ median healing, Figure 3 ); however, none of these changes was significant with respect to baseline. Normal skin TGF- $\beta$ levels increased by week 4 (data not shown), whereas changes throughout the study period were negligible for ulcer edges, ulcer centers, and wound fluid levels (Table 2). TNF- $\alpha$ and IL-1 $\beta$ were always significantly different from baseline plasma levels. The IL-1 $\beta /$ IRAP ratio appeared to follow a biphasic response profile in the wound fluids when compared with healing (Figure 4, $A)$ and was significantly different from its baseline

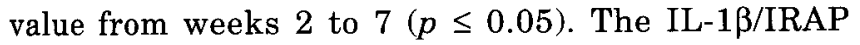
ratio showed a significant increase from the ulcer center tissues and was statistically correlated with the degree of wound closure (Figure $4, B ; p \leq 0.05$ ). This ratio declined between baseline and week 4 in the ulcer edges, but these changes were not significantly associated with healing (Figure $4, B$ ).

\section{CC chemokine levels at baseline and throughout the wound healing process}

At baseline, MCP-1, MIP- $1 \alpha$, and MIP-1 $\beta$ in both tissue and wound fluid were elevated in comparison with normal skin and plasma levels (Table 2). MIP-1 $\beta$ declined during the healing process until approximately week 4 and showed a subsequent rise toward the end of the observation (results not shown). During the healing process, there was a slight increase in MCP-1 within the tissues (results not shown). Only the rise in MIP- $1 \alpha$ in the ulcer center (between weeks 0 and 4 ) was significant $(p \leq 0.05)$, and only the changes in normal skin MCP-1 levels correlated with wound closure $(p \leq 0.05)$. Thus, the more potent macrophage chemoattractants (MCP-1 and MIP-1 $\alpha$ ) followed a trend toward gradual increases in ulcer levels during healing; whereas, the reverse was seen for MIP-1 $\beta$, which predominantly affects $T$ cells.

Wound fluids extracted from dressing samples showed no significant trends for the $\mathrm{CC}$ chemokines over the 8-week study period when compared with baseline levels. RANTES was significantly higher at baseline only in wound fluid samples $(p \leq 0.05)$ as compared with tissue or plasma levels, but it also trended toward lower levels with wound closure. When the wound fluid levels of the $\mathrm{CC}$ chemokines were compared with plasma levels, individual expression profiles were evident, as seen with the CXC chemokines. Of note were changes in RANTES, which was always significantly different $(p \leq 0.005)$ from plasma levels. Significant differences were also seen in MIP-1 $\alpha$ (weeks 1 and 3 to 8 ), and MIP-1 $\beta$ (weeks 1,5 , and 8) with respect to the baseline wound fluid levels.

\section{DISCUSSION}

In this study, we have investigated tissue and wound fluid levels of the recently characterized family of chemoattractants, the chemokines, in a controlled series of patients with CVIUs who were all treated with a standardized compression dressing. The $\mathrm{CC}$ chemokine subfamily principally has its effects on mononuclear cell function and would be predicted as important in the midand later-phases of wound healing; whereas, the CXC chemokine subfamily primarily affects neutrophils and lymphocytes, with both angiogenic and angiostatic proteins characterized. However, as with most cytokines, both subfamilies also include multifunctional members, with effects reported on virtually every cell type in the wound repair response. ${ }^{6,8,11,20}$ We describe a dynamic cytokine profile that may help to provide insight into the pathogenesis of CVIUs.

We have found that baseline CVIUs are characterized by a CXC chemokine phenotype that overwhelmingly favors the antiangiogenic effects of PF4 and IP10, the so-called ELR-chemokines. The predominant ELR- chemokine in untreated CVIUs was PF4, whereas the predominant ELR+ chemokine was NAP2. These findings were the same as those for the patients' normal skin and plasma, as well as for the relative levels reported for CXC chemokines in normal human plasma and bronchoalveolar-lavage fluids. ${ }^{11}$ Chronic wound fluids from these patients had a mean baseline PF4 level 14-fold higher than that seen in normal human plasma and almost 77 -fold that of normal bronchoalveolar-lavage fluid. ${ }^{8,10,11}$ It was particularly interesting to find relatively high levels of PF4 in the patients' normal skin (mean $=4416 \pm 2158 \mathrm{ng} / \mathrm{ml} / \mathrm{mg}$; median $=2046)$ in relation to either their plasma (mean $=$ $60,762 \pm 12,670 \mathrm{ng} / \mathrm{ml}$; median $=66,549$ ) or normal human plasma (mean $=4425 \pm 616.9 \mathrm{ng} / \mathrm{ml}$ ), because platelet activation (the primary source of PF4) was not expected to be an important event in normal skin. ${ }^{14}$ Thus, systemic upregulation of CXC expression appears to be present, despite the local nature of the CVIU. Wound fluid results represent the 7-day accumulation of material in the dressing. Because no assessment of the stability of the chemokines in this environment for 7 days was made, it is possible that significant levels of cytokines are not represented in these wound fluid values.

The patients' normal skin samples had a median of $210.2 \mathrm{ng} / \mathrm{ml}$ of IP10 as compared with the untreated CVIUs, which ranged from $0.51 \mathrm{ng} / \mathrm{ml} / \mathrm{mg}$ in the wound fluids to $74.1 \mathrm{ng} / \mathrm{ml} / \mathrm{mg}$ in the ulcer centers and 127.2 $\mathrm{ng} / \mathrm{ml} / \mathrm{mg}$ in the ulcer edges. This was also an unexpected paradox, because this interferon- $\gamma(\mathrm{IFN}-\gamma)$ inducible protein would have been expected to be higher in the inflamed, nonhealing CVIU center and much lower in normal skin (which is relatively devoid of activated $\mathrm{T}$ cells producing IFN- $\gamma^{22}$ ). IFN- $\gamma$ has been shown previously to be a potent inhibitor of both fibroblast and endothelial 
cell growth, having been used effectively for the treatment of keloids and hemangiomas. ${ }^{23,28}$

Chronic wounds are characterized by a polymorphic infiltrate of leukocytes, predominated by lymphocytes and neutrophils and a relative paucity of macrophages. ${ }^{22}$ This histopathology is analogous to many acute and subacute inflammatory processes. We found that the only ELR+ CXC chemokine present in levels higher than in normal skin in the untreated CVIU was IL-8; the other CXC chemokines were all higher in the patients' normal skin. Although no direct measures of angiogenesis were performed in this series of patients with CVIU, angiogenesis is predicted to have been inhibited by the overwhelming levels of ELR- chemokines, despite IL-8 upregulation in the untreated ulcers. IL- 8 is a potent, proinflammatory chemoattractant for neutrophils and $\mathrm{T}$ cells and is known to be increased in chronic wounds. ${ }^{2,4,7}$ Healing was associated with a relative shift in the ratio of ELR+ to ELR- chemokines; yet the overall antiangiogenic effects of PF4 and IP10 predominated, as is the case in normal human plasma. Among the individual chemokines, there was an early peak in IL-8 levels that was followed by progressive increases in NAP2 and GRO $\alpha$. Again, this followed our hypothetical model with the proinflammatory mediators, which may be facilitating the infiltration of $\mathrm{T}$ cells and neutrophils, coincident with the resolution of inflammation and the initiation of wound closure.

Trends seen in the tissue levels of CXC chemokines were not statistically significant in comparison with the percentage of wound closure; thus their direct role in wound healing is only speculative. The differential change in the ELR+/ELR- ratio between the ulcer edge and center, a stable ratio at the ulcer edge, and an increasing ratio in the ulcer center paralleling wound healing, appears to follow the physiology of the healing chronic wound. Increased need for vascularity and angiogenesis characterizes the changes in the poorly healed central portion of the wound, whereas a decreasing requirement for angiogenesis at the margins of the wound allows for epithelial migration..$^{5,6}$ IP10 has been shown to stimulant keratinocyte growth ${ }^{15,24,25}$; and overexpression of its inducer, IFN- $\gamma$, has been implicated in the hyperproliferative state seen in psoriasis. ${ }^{25,26}$ Thus, local increases in IP10 at the ulcer edge may help stimulate keratinocytes to divide and migrate, along with a down regulatory effect on angiogenesis. Antiangiogenic effects are best known clinically for the interferons through their use in the treatment of childhood hemangiomas. ${ }^{27,28}$

Another interesting finding was that there appeared to be a coincident decrease in the levels of NAP2 and IL8 ( $p=0.083$, and 0.07 , respectively) in the normal skin collected sequentially from patients in this clinical trial. This, along with the increases in PF4 found in these patients' plasma and normal skin described previously, further support that the induction of wound healing within CVIUs may be more than a local phenomenon, because significant shifts in the distribution of inflammatory mediators occur throughout the cutaneous and vascular compartments.

In untreated CVIUs, we found there was a slight elevation of all $4 \mathrm{CC}$ chemokines studied, both within the ulcer tissue and in the wound fluids. MIP-1 $\alpha$, MIP-1 $\beta$, MCP-1, and RAN'TES are all chemotactic for T cells and have recently been associated with chronic T-cell mediated inflammatory disorders, including rheumatoid arthritis, pulmonary fibrosis, and chronic nonprogressive HIV infection. ${ }^{8,16,18}$ Although no significant changes were detected in association with healing, there was a trend for levels of MIP- $1 \beta$ and RANTES to fall, analogous to the decreases in the other proinflammatory cytokines described previously. These wounds also appeared to have a trend toward increasing levels of MCP-1 and MIP$1 \alpha$ (the more potent macrophage chemotaxis) in association with healing. ${ }^{20}$ Thus, a parallel shift in mediators from a proinflammatory state to one of inflammation resolution was seen between these four CC chemokines and the shifts observed between the angiogenic and angiostatic CXC chemokines in CVIUs during therapy.

Elevated levels of IL-1 $\beta$ and IL-6 in baseline CVIUs were demonstrated to decrease as healing began. As wound closure proceeded throughout the 8-week trial, there was an inverse change in the ratio of IL- $1 \beta$ to its inhibitor, IRAP, particularly in the tissues from the ulcer center $(p \leq 0.05)$. Thus, just as the angiostatic CXC chemokines decrease with the initiation of therapy in CVIU, so too do the relative levels of IL-1 $\beta$. We suggest that these ratios may be one of the more sensitive immunologic parameters of healing and the concurrent resolution of the chronic inflammatory state present in CVIUs.

Resolution of inflammation is also represented as being coordinated with healing by the changes seen in the levels of IL-10 during the healing process, with a rise noted in the first 4 to 5 weeks in conjunction with progression toward healing. Although not statistically significant, it is interesting that most of the IL-10 detected was recovered from the wound fluids and not from tissue samples. Preliminary data ${ }^{29}$ suggest that these high levels of IL-10 in chronic wound fluid may not be functional, and that some breakdown product may account for the variable levels detected by ELISA in some patients.

These changes in the pro- and anti-inflammatory cytokines and chemokines all point toward a shift in the dynamics of the CVIU occurring during the induction of wound healing. This shift moves from a chronic, pro-inflammatory state characterized by high levels of TNF- $\alpha$, IL-1 $\beta$, IL-6, IL-8, RANTES, and MIP-1 $\beta$ (all known for their effects on the earlier components of the pathway), toward one characterized by increases in anti-inflammatory cytokines that stimulate resolution of inflammation by recruiting mononuclear phagocytes, favoring angiogenesis, 
and inducing keratinocyte migration and fibrogenesis. Increases in IRAP and IL-10 directly shut down the proinflammatory effects of IL-1 $\beta$, IL-2, and IFN $\gamma^{30,31}$

Interpreting these changes suggests that the inhibition of healing may be related to early constituents of the inflammatory process (e.g., polymorphonuclear leukocytes, lymphocytes) and mediated by imbalances in the levels of some of these cytokines. Therapy is associated with decreases in some of these inflammatory mediators, along with increases in those mediators that favor progression toward the characteristics typical of the proliferative and maturation phases of wound repair. Our study shows that increasing monocyte and macrophage cytokines, whose job it is to "mop up" inflammatory reactions, allows progression toward wound closure. Increasing levels of some of these inflammatory mediators (e.g., IL-10, MCP-1, TGF- $\beta$, IRAP, IP10) also may have roles in initiating the proliferation of fibroblasts and keratinocytes, which are necessary for wound closure and remodeling. ${ }^{1,2,24,30,32}$

The lush granulation tissue that characterizes the normal healing wound is principally the result of cytokineinduced vessel proliferation and must occur before epithelial migration..$^{5,32}$ A global shift toward the proangiogenic effect of increased ELR+ chemokines is seen, along with a compartmental change that reflects the cellular dynamics within the CVIUs studied. As the wound begins to heal, and effective granulation tissue is laid down, the inflammatory state changes to one characteristic of the proliferative (i.e., macrophage and fibroblast dominated) stage of healing. Keratinocytes begin to migrate in from the wound edges, and the stimulus for angiogenesis is shut down (as evidenced by the stabilization in relative levels of ELRchemokines at the ulcer edges during therapy). Those mediators that augment macrophage, fibroblast, and keratinocyte functions predominate. ${ }^{6}$

The hypothesis we propose is that the causes of CVIUS are probably multifactorial, but their principal feature, the inability of these wounds to heal, appears to be related to the persistence of the chronic inflammatory state combined with a relative lack of angiogenesis. Dynamic changes are presented that show these ulcers will heal with appropriate compression dressing therapy and wound care. Healing is shown to be characterized by a change from the chronic pro-inflammatory state to one of resolving inflammation and increasing cytogenesis, which parallels an increase in the relative levels of angiogenic chemokines within the nonhealing portions of these ulcers.

\section{ACKNOWLEDGEMENT}

Supported in part by an unrestricted educational grant from Smith and Nephew United, Largo, Florida, and by National Institutes of Health Grant Nos. CA66180 (RMS) and CA69568 (RMS).

\section{REFERENCES}

1. Falanga V. Chronic wounds: pathophysiologic and experimental considerations. J Invest Dermatol 1993;100:721-5.

2. Jyung RW, Mustoe TA. Role of cytokines in wound repair. In: Oppenheim J, editor. Clinical applications of cytokines. New York: Oxford Univ Press;1993.p.307-29.

3. Mauviel A, Uitto J. The extracellular matrix in wound healing: role of the cytokine network. Wounds 1993;5:137-52.

4. Li V, Barnhill R. Angiogenesis in dermatology: pathophysiology and clinical implications. Prog Derm 1995;29:1-12.

5. Margolis DJ, Cohen JH. Management of chronic venous leg ulcers: a literature guided approach. Clinics Dermatol 1994;12:19-26.

6. Davidson JM. Wound repair. In: Gallin JI, Goldstein IM, Snyderman R, editors. Inflammation: basic principles and clinical correlates. New York: Raven Press;1992.p.???

7. Falanga V. Growth factors and wound healing. Dermatol Clinics 1993;11:667-75.

8. Streiter RM, Kunkel SL. Chemokines and the lung. In: Crystal R, West J, Weibel E, Barnes ???, editors. The lung: scientific foundations. 2nd ed. New York: Raven Press; 1996.p.???

9. Walz A, Baggiolini M. Generation of the neutrophil-activating peptide NAP2 from platelet basic protein or connective tissue-activating peptide III through monocyte proteases. J Exp Med 1990;171:449-54.

10. Baggiolini M, Dewald B, Moser B. Interleukin-8 and related chemotactic cytokines-CXC and CC chemokines. Adv Immunol 1994;55:97-149.

11. Strieter RM, Lukacs NW, Standiford TJ, Kunkel SL. Cytokines and lung inflammation. Thorax 1993;48:765-9.

12. Koch AE, Polverini PJ, Kunkel SL, Harlow LA, DiPietro LA, Elner VM, Elner SG, Strieter RM. Interleukin-8 (IL-8) as a macrophage-derived mediator of angiogenesis. Science 1992;258:1798-801.

13. Taub DD, Oppenheim JJ, Review of the chemokine meeting: the Third International Symposium of Chemotactic Cytokines. Cytokine 1993;5:175-9.

14. Maione TE, Gray GS, Petro J, Hunt AJ, Donner AL, Bauer SI, Carson HF, Sharpe FJ. Inhibition of angiogenesis by recombinant human platelet factor-4. Science 1990;247:77-9.

15. Strieter RM, Kunkel SL, Arenberg DA, Burdick MD, Polverini PJ. Interferon $\gamma$-inducible protein 10 (IP10) a member of the CXC chemokine family is an inhibitor of angiogenesis. Biochem Biophys Res Comm 1995;210:51-7.

16. Cocchi F, deVico AL, Garzino-Demo A, Arya SK, Gallo RC, Lusso P. Identification of RANTES, MIP-1 $\alpha$ and MIP-1 $\beta$ as the major HIV-suppressive factors produced by CD8+ T cells. Science 1995;270:1811-5.

17. DiPietro LA, Polverini PJ. Angiogenic macrophages produce the angiogenic inhibitor thrombospondin 1 . Am $\mathrm{J}$ Pathol 1993;143:678-84

18. Kasama T, Streiter RM, Lukacs NW, Lincoln PM, Burdick MD, Kunkel SL. Interleukin 10 expression and chemokine regulation during the evolution of murine type II collageninduced arthritis. J Clin Invest 1995;95:2868-76.

19. Kasama T, Streiter RM, Lukacs NW, Lincoln PM, Burdick MD, Kunkel SL. Regulation of neutrophil-derived chemokine expression by IL-10. J Immunol 1994;152:3559-69.

20. Fahey TJ, Sherry B, Tracey KJ, van Deventer S, Jones WG, Minei JP, Morgello S, Shires GT, Cerami A. Cytokine production in a model of wound healing: the appearance of MIP-1, MIP-2, cachectin/TNF and IL-1. Cytokine 1990;2:92-9.

21. Fivenson DP, Faria DT, Nickoloff BJ, Poverini PJ, Strieter RM. Biological wound dressings function as a reservoir for C-X-C chemokines in chronic venous ulcer therapy [abstract]. Clin Res 1994;42:232.

22. Herrick SE, Sloan P, McGurk M, Freak L, McCollum CN, Ferguson MWJ. Sequential changes in the histologic pattern 
and extracelluar matrix deposition during healing of chronic venous ulcers. Am J Pathol 1992;141:1085-95.

23. Granstein RD, Rook A, Flotte TJ, Amento EP. A controlled trial of intralesional recombinant gamma interferon in the treatment of keloidal scarring. Arch Dermatol $1990 ; 126: 1295-8$.

24. Luster AD, Leder P. IP10, a C-X-C-chemokine, elicits a potent thymus-dependent antitumor response in vivo. J Exp Med 1993;178:1057-65

25. Gottleib AB, Luster AD, Posnett DN, Carter DM. Detection of $\gamma$-interferon-induced protein (IP-10) in psoriatic scales. J Exp Med 1988;168:941-8.

26. Uyermura K, Yamamura M, Fivenson DP, Modlin RL, Nickoloff BJ. The cytokine network in lesional and lesion-free psoriatic skin is characterized by a T-helper type 1 cell mediated response. J Invest Dermatol 1993;101:701-5.

27. Sidky YA, Borden EC. Inhibition of angiogenesis by interferons: effects on tumor- and lymphocyte-induced vascu- lar responses. Cancer Res 1987;47:5155-61.

28. Vitale MK, Willwerth-Fortin J, Robbins K. Management of children on interferon therapy. Pediatr Nurs 1993;19:230-4.

29. Hou Z, Faria DT, Strieter RM, Ladin DA, Fivenson DP. Suppressive effects of IL-10 on T-cell mitogenesis in chronic wound fluid [abstract]. J Invest Dermatol 1996;106:941.

30. Kim J, Modlin RL, Dubinett SM, McHugh T, Nickoloff BJ, Uyemura K. IL-10 production in cutaneous basal and squamous cell carcinoma: a mechanism for evading the local $\mathrm{T}$ cell immune response. J Immunol 1995;155:2240-7.

31. de Haan P, Sampat S, van der Raaij EM, Bruynzeel I, Boorsma DM, Willemze R, Stoof TJ. Effect of calcitriol on growth, differentiation, chemokine mRNA expression of cultured keratinocytes and on keratinocyte-T cell binding. Acta Derm Venereol Suppl (Stockh) 1994;186:52-4.

32. Hammerberg C, Arend WP, Fisher GJ, Chan LS, Berger AE, Haskill JS, Voorhees JJ, Cooper KD. Interleukin-1 receptor antagonist in normal and psoriatic epidermis. J Clin Invest 1992;90:571-83. 